\title{
Analysis of Aspects of Innovation in a Brazilian Cluster
}

\author{
Adriana Valélia Saraceni', Pedro Paulo de Andrade Júnior²
}

\begin{abstract}
Innovation through clustering has become very important on the increased significance that interaction represents on innovation and learning process concept. This study aims to identify whereas a case analysis on innovation process in a cluster represents on the learning process. Therefore, this study is developed in two stages. First, we used a preliminary case study verifying a cluster innovation analysis and it Innovation Index, for further, exploring a combined body of theory and practice. Further, the second stage is developed by exploring the learning process concept. Both stages allowed us building a theory model for the learning process development in clusters. The main results of the model development come up with a mechanism of improvement implementation on clusters when case studies are applied.
\end{abstract}

Keywords: learning process; innovation; industrial cluster; theory model.

\footnotetext{
' Production Engineering Post Graduation Program (Programa de Pós Graduação em Engenharia da Produção - PPGEP), Universidade Tecnológica Federal do Paraná - UTFPR.Av. Monteiro Lobato s/n Km 04 CEP 840 I6-20I. Ponta Grossa, PR, Brasil - Fone/Fax: +55 42 32204800 Email: avsaraceni@hotmail.com ${ }^{2} \mathrm{PhD}$, Professor.

Production Engineering Post Graduation Program (Programa de Pós Graduação em Engenharia da Produção - PPGEP), Universidade Tecnológica Federal do Paraná - UTFPR.Av. Monteiro Lobato s/n Km 04 CEP 840 I6-20I. Ponta Grossa, PR, Brasil - Fone/Fax: +55 42 32204800 Email: pedropaulo@utfpr.edu.br
} 


\section{INTRODUCTION}

Business process re-engineering is a tool for fundamental review of business processes, providing vast opportunities for significant change improvements and of continuous ongoing improvement (Buckler, 1996). The business process success depends on the ability to create an environment where learning and innovation can be facilitated (Buckler, 1996; Maehler et al., 20II).

Buckler's learning process model helps organizations to achieve better business results. Thereby, helps the enterprises to achieve continuous improvement and innovation (Yeo, 2005).

Withal, measuring innovation performance provides important diagnoses on the continuous process to achieve innovation. It also provides possible pathways for new innovation strategies (Wonglimpiyarat, 20l0).

Another important aspect of the innovation processes emphasis knowledge share as one of the main pillars in the process (Buckler, 1996; Maskell, 200I; Srivastava, 20I I; Maehler et al., 20l I). The interaction processes that occur on Industrial Clusters are known as the most effective to enhance learning process (Maskell, 200I).

Buckler's (1996) learning process model suggests that learning need a diagnosis and progress review. By providing the diagnosis and progress review, this research is developed by the challenge to answer the question:What does an innovation diagnosis represent in the cluster learning process?

In the aim of answering the question, this study is developed in two stages. Initially, the main goal is to analyze a diagnosis and progress review in a cluster. To build this framework, we used a preliminary case study on innovation analysis and Innovation Index, aiming to explore a combined body of theory and practice. Further, the second stage is developed analyzing the learning process concept for sequentially, build a theory model on which innovation diagnosis and progress review are mechanism of improvement implementation on firms and clusters.

\section{INNOVATION PROCESS}

Innovation is defined as the successful process of introduction something new and useful such as methods, techniques, or practices covering the full value chain, including marketing, advertising, sales, distribution and customer service. Moreover, the definition of innovation applies for new or altered products and services (Bigliardi et al., 20 II; Cropley et al., 20II).
By exploring the determinants on the innovation processes, the literature emphasis knowledge share as an effective key to the process (Buckler, 1996; Maskell, 200 I; Srivastava, 20I I; Maehler et al., 20II).

As Weidenfeld et al. (2010) points out, "the knowledge transfer process is also a learning process that results in the creation of stocks of knowledge embedded within an organization. These may directly inform the innovation process and will to varying degrees stimulate and shape future learning". Thereby, knowledge management and structures that support organizational learning, flows the development of the innovation by the information sharing processes (Srivastava, 20I I).

Besides, information obtained from the environment plays an important role in the process of generating innovation because of the complementary role to existing data and information within the firm (Maehler et al., 20l I).

Generating innovation takes place internally in the firm, by research and development (R\&D) areas, investments in science and technology. It also takes place by means of interaction. The process of accessing new knowledge may be by interacting with customers, suppliers, competitors (Maehler et al., 20II), universities and companies, between research institutes and companies; between two or more universities and many different institutional arrangements. The interaction processes goes through the creation, dissemination and application of knowledge (OECD, 2005; Weidenfeld et al., 2010; Balbinot et al., 2012).

The interaction process lead us to most popular interaction model called Industrial Clusters, of which has "been selected in recent years by scholars from a number of different disciplines as the territorial configuration most likely to enhance learning process" (Maskell, 200I).

Therefore, the inter-firm network occurred within the cluster transformed itself to a space for social innovation (Anbumozhi et al., 20I0), of which happens because co-located firms within related industrial enhance the ability to create knowledge by variation and a deepened division of labor (Maskell, 200I).

Moreover, the transfer and dissemination of "ideas, skills, knowledge, information and signs" is stressed as a key factor by systemic view of innovation (OECD, 2005), of which is a learning process in enterprises is assimilation process which produces and disseminates new knowledge (Lopes and Judice, 20I I).

In this way, by cooperative actions, the performance of the innovation process tends to strengthen in the industrial cluster (Gerolamo et al., 2008). 
Hence, once Industrial Clusters are the territorial configuration most likely to enhance learning process, dissemination and transfer of ideas, skills, knowledge, information and signs would easily happen, leading for a process that generate innovation.

Accordingly, the analysis on a Cluster Innovation Process is necessary. Cooperation followed by evaluation the process performance promotes the continuous innovation (Saraceni and Andrade Júnior, 2012a). Measuring Innovation process provide possible pathways to policy challenges and new innovation strategies (Wonglimpiyarat, 2010). The importance of innovation diagnosis is not solely aimed at the enterprises, but is aimed at the cluster, the regional level and to the learning process development.

\section{LEARNING PROCESS CONCEPT}

The learning process models are center in two extreme versions. The first, Buckler (1996) called the "taught model", where learning in general is something which is "done to" people. The second one he called "discovery model", which describes something people "do" for themselves. Based on the extreme versions of the models, Buckler (1996) considered an infinite range of options in between. From that approach, he related the relative benefits of each learning model, precisely to the objectives of the business process being considered. His model is centered to help organizations achieve better business results. Thereby, helps the enterprise process to achieve continuous improvement and innovation (Yeo, 2005).

The learning requirements, which will provide the focus for learning activity, will need to come directly from the requirements of the business process to which they are relate and to the specific needs of the individuals working within that process (Buckler, 1998).
Robertson et al. (2012) suggests that the innovation process incorporated in the network frameworks allow greater degrees of distributed knowledge and learning. The explicitly address real transformation. Notwithstanding, firms in a cluster become increasingly engaged in the process of learning and continuous improvement, on which their survival depends (Maskell, 200I). Beyond the knowledge and learning process, the enterprise engages on solutions that are available and viable for their improvement.

\section{METHODS}

This paper is developed in two stages:

The first one is by the results of a previous case study, of which used an appropriate technique to provide the innovation index of a Brazilian Cluster. It was analyzed the performance of effort and results to obtain innovation, including investments in human resources, research and development, financial investment, organizational configuration, organizational culture, management practices of technology and innovation, and, the maturity degree in the innovation processes (Saraceni and Andrade Júnior, 20I2b). According to Reis' et al. (2010) instrument of valuation the Enterprises' Innovation Index, the maximum degree of innovation is represented by I, comprising 0.5 of Efforts for Innovation Index and 0.5 Results of innovation index. Table I show each areas compose Efforts and Results.

The second stages happen based on the previous one: this moment, the investigation is to represent whereas in the innovation analysis represent on the learning process. According to Buckler (1998), learning has been defined as "a process that results in changed behavior in ways that lead to improved performance", of which can be applied to different levels, such as learning at an individual, team or organizational. It also makes explicit the linkage between learning and performance. Learning definition embraces acquisition

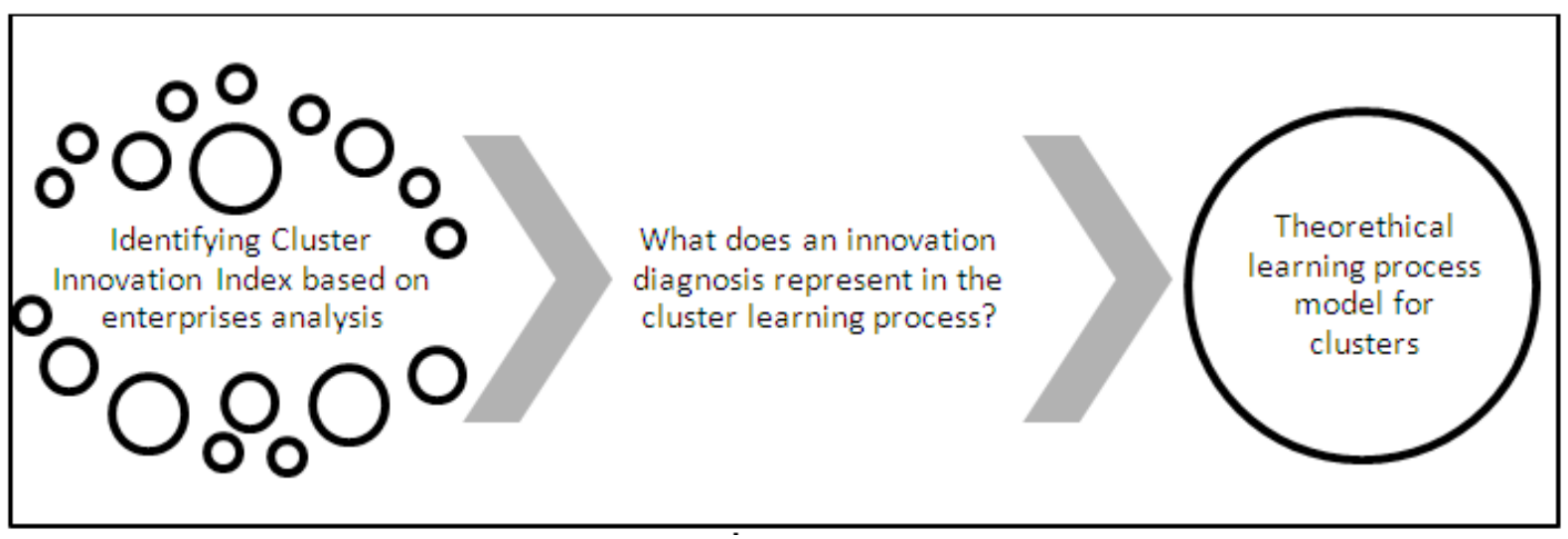

Figure I: Stages of the paper development

ISSN: 07 I8-2724. (http://www.jotmi.org)

Journal of Technology Management \& Innovation (C) Universidad Alberto Hurtado, Facultad de Economía y Negocios. 


\begin{tabular}{|c|c|}
\hline \multicolumn{2}{|c|}{ Cluster Innovation Index: } \\
\hline \multicolumn{2}{|c|}{ Enterprises' Innovation Index IIE $\geq 0$ and $\leq 1=(0.5 \mathrm{x}$ IEI $)+(0.5 \mathrm{x}$ IRI $)$} \\
\hline Efforts for Innovation Index: IEI & Results of Innovation Index: IRI \\
\hline IRH: Human Resources Investments to R\&D\&I & NPI: Number of Innovation Projects \\
\hline IPD: Financial Investment in R\&D\&I & $\begin{array}{l}\text { PFI: Percentage of Revenue coming from new prod- } \\
\text { ucts or services }\end{array}$ \\
\hline TIR: Type of Investment & EID. Coct arinos roculting from ingention in intorn \\
\hline COI: Organizational Configuration for Innovation & $\begin{array}{l}\text { EIP: Cost savings resulting from innovation in interna } \\
\text { processes }\end{array}$ \\
\hline EFI: Physical Structure aimed at R\&D\&I & VTT: Sale of own technology to third parties \\
\hline CUL: Organizational Culture to Innovation & PAT: Number of patents applied for or granted \\
\hline $\begin{array}{l}\text { PGT: Management Practices for Innovation and Tech- } \\
\text { nology }\end{array}$ & PRE: Awards received related to Innovation \\
\hline GMI: Maturity Degree in the Innovation Process & \\
\hline
\end{tabular}

Table I: Saraceni and Andrade Júnior (20I2b) analysis: researched areas

and development of both existing and new knowledge. Also, it considers attitudes and skills in the application of knowledge in new contexts or in the existing ones. The application of knowledge, attitudes and skills seeks on improving the organization performance. For that, it is explored the Buckler (1996) model of learning process to achieve continuous improvement and innovation based on the previous Case Study results. It is also explored the standard variation of the researched big areas to identify the gaps to be improved by the theory model.

\section{RESULTS AND DISCUSSION}

The diagnoses made through the case study provide a range of information about the innovation process. Measuring enterprises innovation capacity provides the diagnoses on the innovation index of which might help to assess what the com- panies should do to improve innovation performance (Weerawardena, 2003; Rejeb et al., 2008; Nidumolu et al., 2009; Wonglimpiyarat, 20I0). Saraceni and Andrade Júnior (2012b) research contributes to identify some important rates of innovation, on each specific area, as showed on the Table 2:

Analyzing technological and organizational aspects on varying degrees play an important role on the understanding of the business needs (Manley et al., 2009). We calculate the standard variation, which also make possible to identify that efforts are more homogeneous that results of Innovation. It is also clear that Sale of own technology to third parties (VTT), Number of patents applied for or granted, Awards received related to Innovation (PRE) are barely happing in the cluster. These three issues are much related to the individual potential, behavior and creativity on innovation process of each interviewed enterprise.

\begin{tabular}{|c|c|c|c|c|c|c|c|c|c|c|c|c|c|c|c|c|}
\hline INDICATORS & IRH & IPD & TIR & $\mathrm{COI}$ & EFI & CUL & PGT & GMI & IEI & NPI & PFI & EIP & VTT & PAT & PRE & IRI \\
\hline TOTAL & 0 & 3.92 & 0.93 & 0.565 & 0.03 & 0.89 & 0.6 & 1.02 & 7.95 & 0.9 & 2.16 & 0.48 & 0 & 0 & 0 & 3.54 \\
\hline AVERAGE & 0 & 0.28 & 0.07 & 0.04 & 0 & 0.06 & 0.04 & 0.07 & 0.568 & 0.1 & 0.15 & 0.03 & 0 & 0 & 0 & 0.253 \\
\hline $\begin{array}{l}\text { ST DEV } \\
(99.9 \%)\end{array}$ & & & & & & & & & 0.1476 & & & & & & & 0.1948 \\
\hline
\end{tabular}

$$
I I E_{C}=(0.5 \times 0.568)+(0.5 \times 0.253)=0.4105
$$

Table 2: Innovation analysis

ISSN: 07 I8-2724. (http://www.jotmi.org)

Journal of Technology Management \& Innovation (c) Universidad Alberto Hurtado, Facultad de Economía y Negocios. 


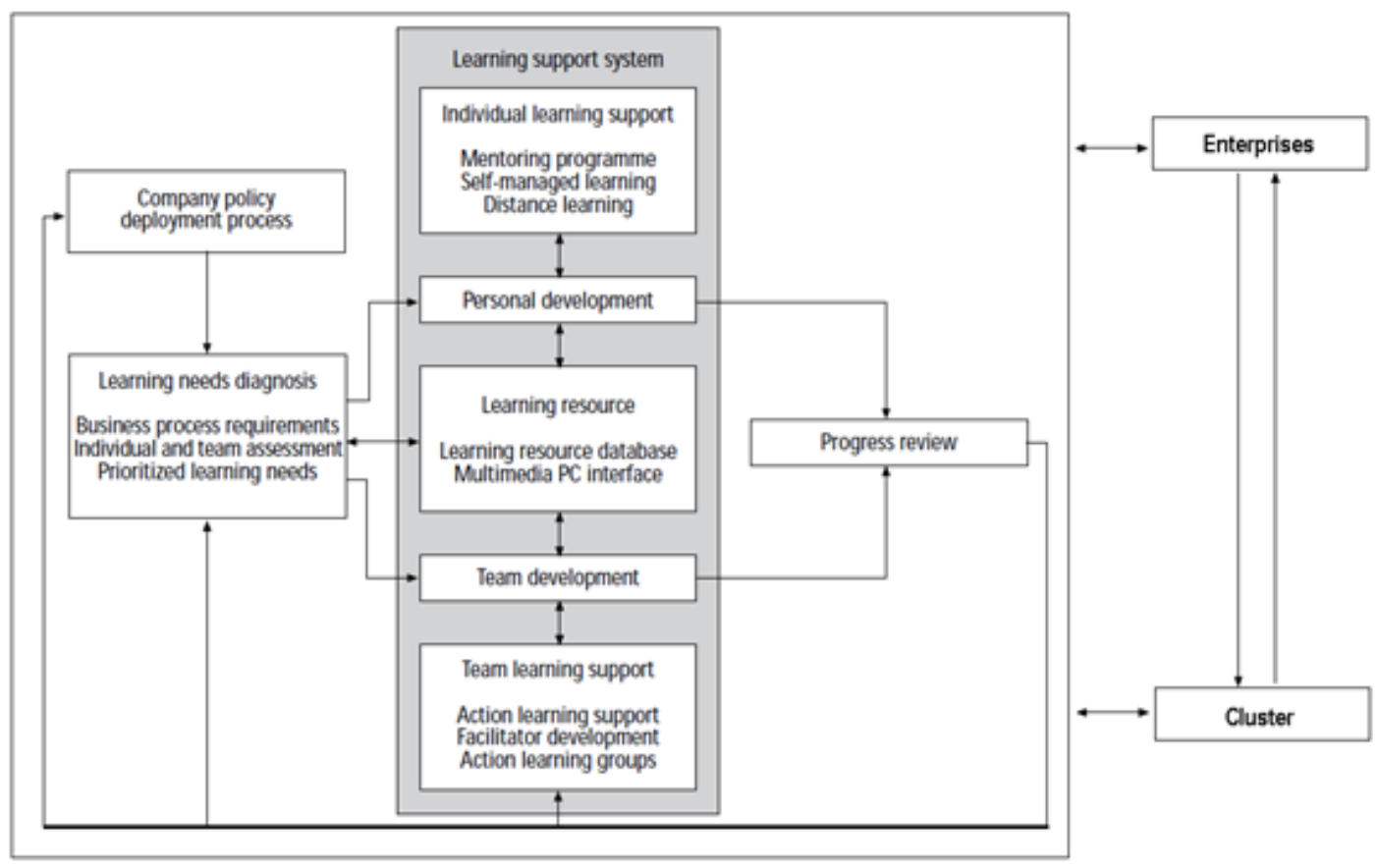

Figure 2: Bringing Buckler's (1996) learning process model to the clusters

Nevertheless the release of individual potential, resulting in behavioral change and creative and innovative process improvements will only really happen if existing learning systems move radically towards the findings (Yeo, 2005).

Buckler's learning process model is developed to help organizations achieve better business results (Yeo, 2005). Bringing this model for each enterprise of the cluster, the result reflects for whole network. Where Buckler's learning process model calls "process review", we added the cluster diagnosis Innovation. The case analysis acts on the Learning Support System. For this study, both the individual and team are considered both contexts: in the enterprises context and the cluster context.

Individually, but composed by its team, the enterprise needs to assess its own situations accurately and must also have a good appreciation of the availability of capabilities in it external environments (Robertson et al., 20I2). Nonetheless, the cluster needs to assess its own situations by knowing the enterprises one. By that, they will be able of improve the availability of capabilities in the environment, building the cycle our model proposes.

\section{CONCLUSIONS}

This framework was based on a previous case analysis of data stream from innovation approaches of performance of effort and results in a Brazilian cluster.The research includes investments in human resources, research and development, financial investment, organizational configuration, organizational culture, management practices of technology and innovation, and, the maturity degree in the innovation processes.

Based on the previous diagnosis, it was possible to identify the areas to be developed allow managers of firms ought to consider alternative innovative solutions, providing efforts to explore new strategies in relationships and in the organizational and technological opportunities, contributing to an increase in the probabilities to generate innovation.

By applying Buckler's learning process model, we could identify that the case analysis process will only be really effective in an environment where the views and opinions of everyone working in the business process are valued by managers at all levels, including cluster managers. Moreover, bringing his model for the cluster environment, we could identify that any strategy taken from the individuals (workers), individual enterprises, and the cluster reflects on each others.

\section{ACKNOWLEDGEMENTS}

Thanks to Capes partials support for this work.

\section{REFERENCES}

ANBUMOZHI, V, GUNJIMA, T, ANANTH, A. P, VISVANATHAN, C. (2010). An assessment of inter-firm networks in a wood biomass industrial cluster: lessons for integrated policymaking. Clean Techn Environ Policy, 12:365-372.

ISSN: 07I 8-2724. (http://www.jotmi.org) 
BALBINOT, Z., DIAS, J. C., BORIM-DE-SOUZA, R. (20I2). Unique Organizational Competencies of Brazilian Technological Innovation Centers, Journal of Technology Management \& Innovation. 7(I), I-I6.

BIGLIARDI, B., COLACINO, P., DORMIO, A. I. (20I I). Innovative Characteristics of Small and Medium Enterprises. Journal of Technology Management \& Innovation. 6(2) 83-93.

BUCKLER, B. (1996). A learning process model to achieve continuous improvement and innovation. The Learning Organization 3(3), 3I-39.

BUCKLER, B. (1998). Practical steps towards a learning organization: applying academic knowledge to improvement and innovation in business processes. The Learning Organization, 5(I) I5-23.

CROPLEY, D. H.; KAUFMAN, J. C.; CROPLEY, A. J. (20II). Measuring Creativity for Innovation Management. Journal of Technology Management \& Innovation. 6(3), 13-30.

GEROLAMO, M. C. CARPINETTI, L. C. R. SELIGER, G. GALDAMEZ, E.V. C. (2008). Performance management of regional clusters and SME cooperation networks. International Journal of Business Excellence. I (4) 457-483.

LOPES, A. L. M., JUDICE, V. M. M. (20II). Technological Effort and Innovative Performance in Brazilian Bio Companies. Journal of Technology Management \& Innovation 6(4) 243257.

MAEHLER, A. E., MARQUES CURADO, C. M., AVILA PEDROZO, E., PIRES, J.P. Knowledge Transfer and Innovation in Brazilian Multinational Companies. Journal of Technology Management \& Innovation. 6(4), I-I4.

MANLEY, K., MCFALLAN, S.AND KAJEWSKI, S. (2009). The relationship between construction firm strategies and innovation outcomes', Journal of Construction Engineering and Management. 35(8) 764-77I.

MASKELL, P. (200I). Toward a knowledge-based theory of the geographical cluster. Industrial and Corporate Change. I0(4) 92I-943.

NIDUMOLU, R., PRAHALAD C. K., RANGASWAMI, M. R. (2009). Why sustainability is now the key driver of innovation. Harvard Business Review. 87: 57-64.

OECD (2005). Guidelines for Collecting and Interpreting Technological Innovation Data. Oslo Manual, OECD, Paris.

REIS, D. (20I0). In: Gerenciar a Inovação, um desafio para as empresas. Fayet, EA (org.). Curitiba:IEL/PR, p. 188.
REJEB, H. B.; MOREL-GUIMARÃES, L. BOLY, V. ASSIÉLOU, N'DOLI G. (2008). Measuring innovation best practices: improvement of an innovation. Technovation 28, 838-854.

ROBERTSON, P. L., CASALI, G. L., JACOBSON, D. (20I2). Managing open incremental process innovation: absorptive capacity and distributed learning. Research policy. 4I(5) 822 -832 .

SARACENI, A.V., ANDRADE JÚNIOR, P. P. (20I2a). Environmentally sustainable innovation process in Industrial Clusters: the Brazilian case. International Journal of Arts and Commerce. I (3).

SARACENI,A.V.,ANDRADE JÚNIOR, P. P. (20I2b). Research of innovation index in a Latin America cluster.African Journal of Business Management, 6(35), 9790-9796.

SRIVASTAVA, M. (20I I).A Case Study and Survey-Based Assessment of the Management of Innovation and Technology. Journal of Technology Management \& Innovation. 6(I) I47160.

WEERAWARDENA, J. (2003). Exploring the role of market learning capability in competitive strategy. European Journal of Marketing, 37(3/4), 407.

WEIDENFELD, A., WILLIAMS, A. M., BUTLER, R.W. (20I0). Knowledge transfer and innovation among attractions. Annals of Tourism Research, 37(3), 604-626.

WONGLIMPIYARAT, J. (2010). Innovation index and the innovative capacity of nations. Futures 42: 247-253.

YEO, R. K. (2005). Revisiting the roots of learning organization: A synthesis of the learning organization literature. The Learning Organization, 12(4), 368-382. 
J.Technol. Manag. Innov. 2012,Volume 7, Issue 3

ISSN: 07I8-2724. (http://www.jotmi.org)

Journal of Technology Management \& Innovation @ Universidad Alberto Hurtado, Facultad de Economía y Negocios. 